Published in final edited form as:

Int J Lab Hematol. 2015 May ; 37(Suppl 1): 11-17. doi:10.1111/ijlh.12345.

\title{
Laboratory diagnosis of von Willebrand disease
}

\author{
J. C. ROBERTS ${ }^{\star}$ and V. H. FLOOD ${ }^{\dagger} \neq$ \\ *Bleeding \& Clotting Disorders Institute, Peoria, IL, USA \\ †Division of Hematology/Oncology, Department of Pediatrics, Medical College of Wisconsin, \\ Milwaukee, WI, USA \\ ¥Children’s Research Institute, Children’s Hospital of Wisconsin, Milwaukee, WI, USA
}

\section{SUMMARY}

Von Willebrand disease (VWD) is considered the most common inherited bleeding disorder and may also be the most difficult to diagnose. Clinical symptoms of VWD include predominantly mild mucosal bleeding; surgical bleeding may occur with specific challenges and joint bleeding can occur in the most severe forms. A family history either of diagnosed VWD or of bleeding symptoms is typically present. Laboratory diagnosis requires a series of assays of von Willebrand factor (VWF) quantity and function, and factor VIII activity, with no single straightforward diagnostic test available to either confirm or exclude the diagnosis. Newer assays of VWF function are becoming more available and useful in determining the laboratory diagnosis of VWD.

\section{Keywords}

Von Willebrand disease; von Willebrand factor; platelets

\section{VON WILLEBRAND DISEASE}

Von Willebrand disease (VWD) is a congenital bleeding disorder caused by a deficiency of von Willebrand factor (VWF) and typically characterized by mild mucosal bleeding. VWF plays several key roles in hemostasis, one of which is to link platelets to sites of vessel injury through binding sites for collagen and platelet glycoprotein Iba (GPIba). VWF binds platelet GPIba through the VWF A1 domain and binds vascular collagens via the A1 and A3 domains [1,2]. Another role is to protect circulating factor VIII (FVIII), through VWFFVIII binding in the VWF D'D3 domain [3].

Patients with VWD generally present with mucosal bleeding, including epistaxis, easy bruising, menorrhagia, gingival bleeding, GI bleeding, surgical bleeding (particularly involving mucosal surfaces such as tonsillectomy or wisdom tooth extraction), and in rare

\footnotetext{
Correspondence: Veronica H. Flood, Comprehensive Center for Bleeding Disorders, 8739 Watertown Plank Road, PO Box 2178, Milwaukee, WI 53201-2178, USA. Tel.: +1 414937 6896; Fax: +1 414937 6811; vflood@ mcw.edu. 
cases joint bleeding. As VWD is inherited, most patients have a family history of bleeding symptoms, although symptoms may vary among affected family members.

VWD may be caused by either a quantitative or a qualitative defect in VWF. The quantitative VWF defects are divided clinically into mild-moderate defects, known as type 1 VWD, and severe defects with undetectable VWF, known as type 3 VWD. The qualitative variants are known as type 2 VWD and divided further based upon the specific defect in VWF present. Current classification of the type 2 variants separates these into four groups [4]. Type 2A variants lack the high molecular weight multimer forms of VWF. Type 2B variants also lack high molecular weight multimers, secondary to gain-of-function defects in VWF causing spontaneous binding to platelet GPIb and subsequent clearance of VWFplatelet complexes. A similar gain-of-function defect in platelet GPIb causes platelet-type VWD. Type 2M includes those variants with a defect in platelet binding, but preserved multimer distribution, and also includes collagen-binding defects. Type $2 \mathrm{~N}$ variants have a defect in FVIII binding.

Initial evaluation for VWD requires a combination of screening tests, as no single test can confirm the presence of fully functional VWF. Along with assessment of VWF protein presence, routine screening tests include assessment of VWF-platelet and VWF-FVIII interactions. VWF testing is detailed in Table 1. An algorithm for VWD diagnosis is presented in Figure 1.

\section{VWD SCREENING TESTS}

\section{VWF antigen (VWF:Ag)}

VWF:Ag is a quantitative assessment of the plasma VWF protein level. VWF:Ag can be performed by ELISA or automated latex immunoassay (LIA) [5]. VWF:Ag is generally very reliable and reproducible, but is limited as it only assesses VWF presence, and does not assess VWF function. Therefore, VWD screening requires additional tests of VWF function to identify VWF protein dysfunctions.

\section{VWF ristocetin cofactor activity (VWF:RCo)}

VWF:RCo is the most commonly used test to assess the ability of VWF to bind GPIba. The VWF:RCo assay is widely used, but is limited by high coefficient of variation [6]. In addition, VWF sequence variations in the A1 domain may also affect the VWF:RCo without altering VWF function [7]. New assays that can directly evaluate VWF-GPIba interactions, which are ristocetin independent, have been developed but none are commercially available in the US at this time $[8,9]$. A reliable assay of VWF-platelet interactions could conceivably replace the VWF:RCo and may eliminate the need for VWF:Ag in initial screening for VWD; however, this would still miss type $2 \mathrm{M}$ collagen-binding defects.

\section{Factor VIII activity (FVIII:C)}

FVIII:C measurement is included in initial workup because VWF is a carrier protein for FVIII. Under normal physiologic conditions, FVIII:C/VWF:Ag ratio is approximately 1. In type $2 \mathrm{~N}$, this ratio will be decreased, and in type 3 VWD, FVIII:C will be $<10 \mathrm{IU} / \mathrm{dL}$. As 
type 2N VWD has a specific defect in FVIII binding and may present with normal VWF:Ag and VWF:RCo, assessment of FVIII:C is crucial in the initial workup for suspected VWD.

\section{VWF:RCo/VWF:Ag}

Assessment of the VWF:RCo/VWF:Ag ratio is helpful in triggering the need to perform further testing for type $2 \mathrm{~A}$, type $2 \mathrm{~B}$, or type $2 \mathrm{M} \mathrm{VWD}$, all of which generally have VWF:RCo/VWF:Ag ratio <0.6 [10]. Confirmatory testing, however, is needed to distinguish between the type 2 variants.

\section{VWD CONFIRMATORY TESTS}

\section{VWF multimer distribution}

A decreased VWF:RCo/VWF:Ag ratio should trigger evaluation of VWF multimer distribution, as a normal multimer distribution would lead to a diagnosis of type $2 \mathrm{M}$ and a loss of high molecular weight multimers would signal the presence of either type $2 \mathrm{~A}$ or type 2B VWD. Multimer assessment is generally performed using agarose gel electrophoresis [11] but is time consuming and not performed by all laboratories.

\section{VWF collagen binding (VWF:CB)}

Collagen binding plays two roles in VWF testing. It can serve as a substitute for detection of high molecular weight multimers, although there is some debate regarding the most ideal collagen preparation [12]. In addition, some VWD variants have a specific collagen-binding defect and are classified as type 2M VWD. There have been several case reports of patients with borderline low VWF:Ag and VWF:RCo but significant decreases in type I and/or type III collagen binding [13, 14]. Recently, VWF defects in binding type VI collagen have been reported [15].

\section{VWF-platelet binding (VWF:PB)}

Platelet binding is used to confirm type 2B VWD, where an increase in spontaneous binding to platelets is demonstrated. This assay utilizes commercial platelets and patient plasma, and will demonstrate increased binding in type 2B but no increase in type 2A VWD. If not available, another option is low-dose ristocetin-induced platelet aggregation.

\section{Low-dose ristocetin-induced platelet aggregation (LD-RIPA)}

Spontaneous aggregation to low-dose ristocetin (typically $\$ 0.6 \mathrm{mg} / \mathrm{mL}$, in contrast to the usual dose of $\geq 1 \mathrm{mg} / \mathrm{mL}$ ) is seen in type 2B VWD and platelet-type VWD. To differentiate between the VWD variants, VWF:PB or genetic analysis is required. Detection of type $2 \mathrm{~B}$ VWD is important as desmopressin is typically avoided in these patients and type $2 \mathrm{~A}$ and type 2B VWD otherwise have similar patterns of decreased VWF:RCo/VWF:Ag ratio and absent high molecular weight multimers. Detection of platelet-type VWD is important as treatment requires platelet transfusions. 


\section{VWF-FVIII binding (VWF:FVIIIB)}

VWF:FVIIIB examines the ability of VWF isolated from patient plasma to bind recombinant FVIII and is used to confirm a diagnosis of type $2 \mathrm{~N}$ VWD, where a specific defect in FVIII binding exists [16].

\section{VWF propeptide (VWFpp)}

VWFpp/VWF:Ag ratios are elevated in type 1C, or clearance defects, and in some type 2 VWD variants. VWFpp is typically tested via ELISA [17], although may not be available in all laboratories. Evaluation of response to desmopressin can also identify clearance defects, in that an increase in VWF:Ag may be seen at $1 \mathrm{~h}$, but VWF levels fall back to baseline by 4 $\mathrm{h}$ following desmopressin administration.

\section{VWF gene sequencing}

Use of genetic diagnosis is limited in VWF due to the large size of the VWF gene and high frequency of normal variants. Early reports of some sequence variations as mutations have been called into question by the high frequency of these 'mutations' found in healthy individuals [18]. DNA sequencing may be useful in type 2 VWD, particularly when confirmatory laboratory tests are unavailable or difficult to interpret. A large number of known sequence variations have been reported for type 2 VWD (collected online by the International Society on Thrombosis and Haemostasis).

Sequence variations in type 2 VWD localize to the defective region of VWF. In type 2B and type $2 \mathrm{M}$, where the defect involves platelet binding, mutations are found in the VWF A1 domain. In type $2 \mathrm{~N}$, where the defect involves FVIII binding, mutations are found in the VWF $\mathrm{D}^{\prime}$ and $\mathrm{D} 3$ domains. In type $2 \mathrm{~A}$, defects can either be in the A2 domain (near the site of AD-AMTS13 cleavage) or in the $\mathrm{N}$ or $\mathrm{C}$ terminal multimerization domains [19]. Defects in types 1 and 3 VWD are found throughout the VWF gene, but novel sequence variations should be examined with caution, as not all variants are associated with VWD.

\section{LABORATORY CLASSIFICATION OF VWD}

\section{Type 1 VWD}

Laboratory characteristics of type 1 VWD include a mild to moderate but proportional decrease in both VWF:Ag and VWF:RCo. FVIII:C may be normal or borderline low. Bleeding symptoms range from mild mucosal bleeding to more severe surgical hemorrhage. Bleeding and penetrance in type 1 VWD is variable. Other influences on VWF levels exist; blood type, ethnicity, and modifier genes have all been implicated [20-22]. Exercise and stress can also elevate VWF levels, and careful consideration should be given to repeat testing in symptomatic patients with borderline normal levels.

Diagnosis of type 1 VWD is made when the VWF: Ag and VWF:RCo are decreased, but in proportion to each other (VWF:RCo/VWF:Ag ratio >0.6.) Additionally, if FVIII:C is lower than VWF:Ag, a diagnosis of type 2N VWD should be considered. A discrepancy between VWF:Ag and VWF:RCo, or a family history of a type 2 variant, should prompt evaluation of multimer distribution. VWFpp may be helpful in evaluation for potential clearance defects, 
or type $1 \mathrm{C}$, but is not generally performed as part of a diagnostic workup. Genetic testing is not usually helpful, as not all patients with type 1 VWD have a sequence variation in VWF, and because mutation status is not currently predictive of either clinical symptoms or response to treatment. The only caveat would be in the case of clearance defects, as diagnosis of type 1C VWD would impact treatment by excluding use of desmopressin for affected patients.

The major dilemma in diagnosis of type 1 VWD is the precise cutoff for VWF:Ag and VWF:RCo below which a patient should be considered to have true VWD. There is a wide variation in normal VWF levels, with the lower limit of normal extending down to about $50 \%$ (exact cutoffs vary by laboratory). However, typical normal ranges exclude 5\% of the population, such that $2.5 \%$ of the population would have levels below the lower limit of normal. As VWD is clearly not present in $2.5 \%$ of the population, low VWF levels alone do not confer a diagnosis of VWD. Some groups have argued for a cutoff of $30 \mathrm{IU} / \mathrm{dL}$, while others have suggested $20 \mathrm{IU} / \mathrm{dL}$ or $40 \mathrm{IU} / \mathrm{dL}$ [10]. The incidence of sequence variations in VWF is clearly increased at lower VWF levels. However, the presence of symptoms is also critical. Some patients with VWF levels above a particular cutoff may experience enough symptoms that treatment is warranted, particularly for major surgeries. Therefore, personal and family history, with special attention to an individual patient's response to prior hemostatic challenges, is required. Laboratory findings alone should not be used to make a diagnosis of type 1 VWD.

\section{Type 3 VWD}

Laboratory characteristics of type 3 VWD include undetectable VWF:Ag and VWF:RCo, accompanied by very low FVIII:C and absent VWF multimers. Affected patients may have significant bleeding, including joint bleeds similar to those seen in patients with hemophilia. Some patients require prophylaxis to prevent recurrent bleeding, particularly in the setting of joint damage. Menorrhagia is a prominent feature for women with type 3 VWD and may require multiple treatment modalities for control.

Diagnosis of type 3 VWD is generally straightforward as the VWF:Ag and VWF:RCo will be clearly decreased. Occasionally, patients with type $1 \mathrm{VWD}$ and a clearance defect will also have almost undetectable VWF:Ag and VWF:RCo due to rapid clearance of VWF. In that case, the VWFpp can help distinguish such variants. DNA sequencing is not generally required to establish the diagnosis, but may be useful for prenatal testing.

\section{Type 2 VWD}

Type 2 VWD variants are characterized by a disproportionate decrease in VWF activity, either in terms of platelet binding, FVIII binding, or collagen binding. Bleeding symptoms are generally more severe than those seen in type 1 VWD.

\section{Type 2A VWD}

The combination of decreased VWF:RCo/VWF:Ag ratio and absent high molecular weight multimers can represent either type $2 \mathrm{~A}$ or type $2 \mathrm{~B}$ VWD. In type $2 \mathrm{~A} V W D$, there is no increase in VWF:PB or LD-RIPA, and patients do not present with thrombocytopenia. 
However, testing to rule out type $2 \mathrm{~B}$ VWD is indicated, as desmopressin may be considered for treatment of type $2 \mathrm{~A}$ patients but is generally not used in type $2 \mathrm{~B}$ patients.

Demonstration of a known type $2 \mathrm{~A}$ sequence variation can also confirm the diagnosis, although novel sequence variants should be interpreted with caution.

\section{Type 2B VWD}

Type 2B VWD also presents with decreased VWF:RCo/VWF:Ag ratio and loss of high molecular weight multimers. Diagnosis of a type $2 \mathrm{~B}$ variant is confirmed by demonstration of increased platelet binding through either increased VWF:PB or increased LD-RIPA and must be discriminated from platelet-type VWD. Gene sequencing may also be helpful in demonstrating a known type $2 \mathrm{~B}$ sequence variation. Thrombocytopenia is frequently present in type 2B VWD, but is not a universal symptom [23].

\section{Type 2M VWD}

This category includes patients with decreased VWF: RCo/VWF:Ag ratio and normal multimer distribution. It may also include patients with abnormal VWF:CB but essentially normal VWF:RCo. There is no specific confirmatory test for type 2M VWD. Although gene sequencing may be helpful, novel sequence variations should be interpreted with caution.

\section{Type 2N VWD}

Patients with type 2N VWD present in two groups. One possibility is the inheritance of two alleles with defects in FVIII binding, making the patient homozygous or compound heterozygous for type $2 \mathrm{~N}$ mutations. Some mutations are associated with very low FVIII (approximately $10 \mathrm{IU} / \mathrm{dL}$ ), while others have a milder phenotype (FVIII approximately 20 IU/dL) [4]. Such patients may have normal VWF:Ag and VWF:RCo, but markedly diminished FVIII levels. Type $2 \mathrm{~N}$ VWD may also present with one type $2 \mathrm{~N}$ allele and one type 1 allele, in which case low VWF:Ag and VWF:RCo may also occur. Patients with an isolated decrease in FVIII should receive evaluation to exclude type $2 \mathrm{~N} \mathrm{VWD}$, as this can easily be misdiagnosed as mild hemophilia A.

\section{CONCLUSIONS}

Laboratory evaluation of VWD requires careful correlation of test results and clinical history. While the quantitative VWF deficiencies are relatively easy to diagnose, the qualitative type 2 variants may pose more of a diagnostic challenge. Specific assays of VWF function are therefore required to clarify the type of VWD in order to facilitate optimal treatment of affected patients.

\section{Acknowledgments}

The authors would like to thank the Comprehensive Center for Bleeding Disorders in Milwaukee, Wisconsin, and their fellow Zimmerman Program Investigators for thoughtful discussions on VWD, and the patients with VWD for insight into their condition. 


\section{References}

1. Fujimura Y, Titani K, Holland LZ, Russell SR, Roberts JR, Elder JH, Ruggeri ZM, Zimmerman TS. Von Willebrand factor. A reduced and alkylated 52/48-kDa fragment beginning at amino acid residue 449 contains the domain interacting with platelet glycoprotein ib. J Biol Chem. 1986; 261:381-5. [PubMed: 2934387]

2. Pareti FI, Niiya K, McPherson JM, Ruggeri ZM. Isolation and characterization of two domains of human von Willebrand factor that interact with fibrillar collagen types I and III. J Biol Chem. 1987; 262:13835-41. [PubMed: 3498719]

3. Foster PA, Fulcher CA, Marti T, Titani K, Zimmerman TS. A major factor VIII binding domain resides within the amino-terminal 272 amino acid residues of von Willebrand factor. J Biol Chem. 1987; 262:8443-6. [PubMed: 3110147]

4. Sadler JE, Budde U, Eikenboom JC, Favaloro EJ, Hill FG, Holmberg L, Ingerslev J, Lee CA, Lillicrap D, Mannucci PM, Mazurier C, Meyer D, Nichols WL, Nishino M, Peake IR, Rodeghiero F, Schneppenheim R, Ruggeri ZM, Srivastava A, Montgomery RR, Federici AB. Working Party on von Willebrand Disease Classification. Update on the pathophysiology and classification of von Willebrand disease: a report of the subcommittee on von Willebrand factor. J Thromb Haemost. 2006; 4:2103-14. [PubMed: 16889557]

5. Castaman G, Tosetto A, Cappelletti A, Goodeve A, Federici AB, Batlle J, Meyer D, Goudemand J, Eikenboom JC, Schneppenheim R, Budde U, Ingerslev J, Lethagen S, Hill F, Peake IR, Rodeghiero F. Validation of a rapid test (VWF-LIA) for the quantitative determination of von Willebrand factor antigen in type 1 von Willebrand disease diagnosis within the european multicenter study MCMDM-1VWD. Thromb Res. 2010; 126:227-31. [PubMed: 20650506]

6. Kitchen S, Jennings I, Woods TA, Kitchen DP, Walker ID, Preston FE. Laboratory tests for measurement of von Willebrand factor show poor agreement among different centers: results from the United Kingdom national external quality assessment scheme for blood coagulation. Semin Thromb Hemost. 2006; 32:492-8. [PubMed: 16862522]

7. Flood VH, Gill JC, Morateck PA, Christopherson PA, Friedman KD, Haberichter SL, Branchford BR, Hoffmann RG, Abshire TC, Di Paola JA, Hoots WK, Leissinger C, Lusher JM, Ragni MV, Shapiro AD, Montgomery RR. Common VWF exon 28 polymorphisms in African Americans affecting the VWF activity assay by ristocetin cofactor. Blood. 2010; 116:280-6. [PubMed: 20231421]

8. Favaloro EJ, Mohammed S. Towards improved diagnosis of von Willebrand disease: comparative evaluations of several automated von Willebrand factor antigen and activity assays. Thromb Res. 2014; 134:1292-300. [PubMed: 25300811]

9. Patzke J, Budde U, Huber A, Mendez A, Muth H, Obser T, Peerschke E, Wilkens M, Schneppenheim R. Performance evaluation and multicentre study of a von Willebrand factor activity assay based on GPIb binding in the absence of ristocetin. Blood Coagul Fibrinolysis. 2014; 25:86070. [PubMed: 25192242]

10. Nichols WL, Hultin MB, James AH, Manco-Johnson MJ, Montgomery RR, Ortel TL, Rick ME, Sadler JE, Weinstein M, Yawn BP. Von Willebrand disease (VWD): evidence-based diagnosis and management guidelines, the national heart, lung, and blood institute (NHLBI) expert panel report (USA). Haemophilia. 2008; 14:171-232. [PubMed: 18315614]

11. Ruggeri ZM, Zimmerman TS. Variant von Willebrand's disease: characterization of two subtypes by analysis of multimeric composition of factor VIII/von Willebrand factor in plasma and platelets. J Clin Invest. 1980; 65:1318-25. [PubMed: 6773982]

12. Favaloro EJ. Toward a new paradigm for the identification and functional characterization of von Willebrand disease. Semin Thromb Hemost. 2009; 35:60-75. [PubMed: 19308894]

13. Ribba AS, Loisel I, Lavergne JM, Juhan-Vague I, Obert B, Cherel G, Meyer D, Girma JP. Ser968Thr mutation within the A3 domain of von Willebrand factor (VWF) in two related patients leads to a defective binding of VWF to collagen. Thromb Haemost. 2001; 86:848-54. [PubMed: 11583318]

14. Riddell AF, Gomez K, Millar CM, Mellars G, Gill S, Brown SA, Sutherland M, Laffan MA, McKinnon TA. Characterization of W1745C and S1783A: 2 novel mutations causing defective 
collagen binding in the A3 domain of von Willebrand factor. Blood. 2009; 114:3489-96. [PubMed: 19687512]

15. Flood VH, Gill JC, Christopherson PA, Bellissimo DB, Friedman KD, Haberichter SL, Lentz SR, Montgomery RR. Critical von Willebrand factor A1 domain residues influence type VI collagen binding. J Thromb Haemost. 2012; 10:1417-24. [PubMed: 22507569]

16. Nishino M, Girma JP, Rothschild C, Fressinaud E, Meyer D. New variant of von Willebrand disease with defective binding to factor VIII. Blood. 1989; 74:1591-9. [PubMed: 2506947]

17. Haberichter SL, Balistreri M, Christopherson P, Morateck P, Gavazova S, Bellissimo DB, MancoJohnson MJ, Gill JC, Montgomery RR. Assay of the von Willebrand factor (VWF) propeptide to identify patients with type 1 von Willebrand disease with decreased VWF survival. Blood. 2006; 108:3344-51. [PubMed: 16835381]

18. Bellissimo DB, Christopherson PA, Flood VH, Gill JC, Friedman KD, Haberichter SL, Shapiro AD, Abshire TC, Leissinger C, Hoots WK, Lusher JM, Ragni MV, Montgomery RR. VWF mutations and new sequence variations identified in healthy controls are more frequent in the African-American population. Blood. 2012; 119:2135-40. [PubMed: 22197721]

19. Goodeve AC. The genetic basis of von Willebrand disease. Blood Rev. 2010; 24:123-34. [PubMed: 20409624]

20. Gill JC, Endres-Brooks J, Bauer PJ, Marks WJ Jr, Montgomery RR. The effect of ABO blood group on the diagnosis of von Wille-brand disease. Blood. 1987; 69:1691-5. [PubMed: 3495304]

21. Miller CH, Haff E, Platt SJ, Rawlins P, Drews CD, Dilley AB, Evatt B. Measurement of von Willebrand factor activity: relative effects of $\mathrm{ABO}$ blood type and race. J Thromb Haemost. 2003; 1:2191-7. [PubMed: 14521604]

22. Johnsen JM, Auer PL, Morrison AC, Jiao S, Wei P, Haessler J, Fox K, McGee SR, Smith JD, Carlson CS, Smith N, Boerwinkle E, Kooperberg C, Nickerson DA, Rich SS, Green D, Peters U, Cushman M, Reiner AP. NHLBI Exome Sequencing Project. Common and rare von Willebrand factor (VWF) coding variants, VWF levels, and factor VIII levels in African Americans: the NHLBI exome sequencing project. Blood. 2013; 122:590-7. [PubMed: 23690449]

23. Federici AB, Mannucci PM, Castaman G, Baronciani L, Bucciarelli P, Canciani MT, Pecci A, Lenting PJ, De Groot PG. Clinical and molecular predictors of thrombocytopenia and risk of bleeding in patients with von Willebrand disease type $2 \mathrm{~B}$ : a cohort study of 67 patients. Blood. 2009; 113:526-34. [PubMed: 18805962] 


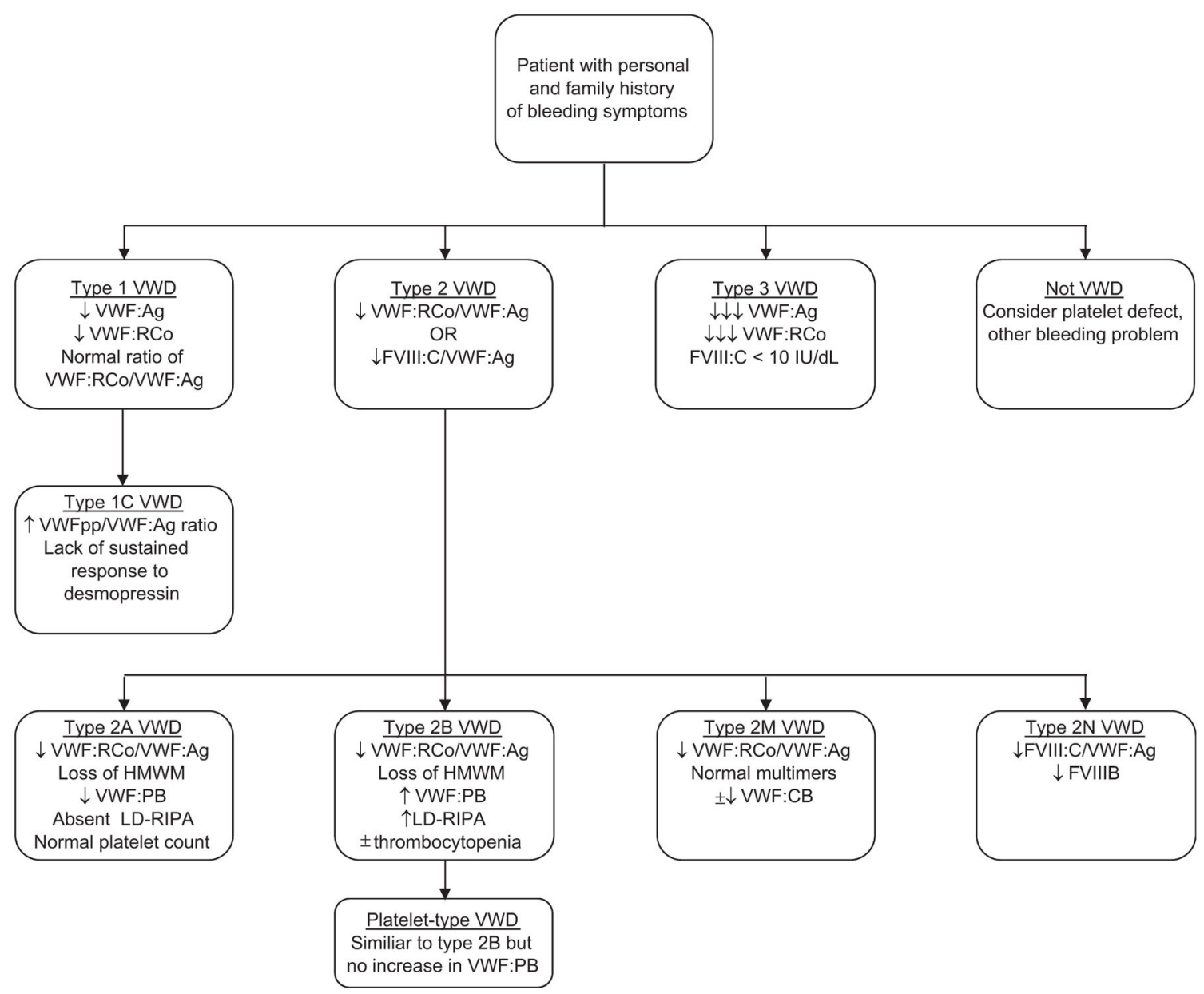

Figure 1.

Flow diagram for diagnosis of VWD. 


\section{Table 1}

\section{Laboratory testing for VWD}

\begin{tabular}{ll}
\hline VWD Screening Tests & \\
VWF:Ag & $\downarrow$ in type $1, \downarrow$ most type 2, undetectable in type 3 \\
VWF:RCo & $\downarrow$ in type $1, \downarrow \downarrow$ most type 2, undetectable in type 3 \\
FVIII:C & $\downarrow$ or normal in type 1, most type 2, $\downarrow$ in type 2N, type 3 \\
VWF:RCo/VWF:Ag ratio & $\downarrow$ in type 2A, 2B, 2M \\
VWD Confirmatory Tests & \\
VWF multimer distribution & Abnormal in type 2A and type 2B \\
VWF:CB & Abnormal in type 2A and type 2B, some type 2M \\
VWF:PB & Increased in type 2B \\
LD-RIPA & Increased in type 2B and platelet-type VWD \\
VWF:FVIIIB & Decreased in type 2N \\
VWFpp & $\uparrow$ VWFpp/VWF:Ag ratio in type 1C \\
VWF gene sequencing & Most helpful in type 2 variants
\end{tabular}

VWF:Ag = VWF antigen; VWF:RCo = VWF ristocetin cofactor activity; FVIII:C = factor 8 activity; VWF:CB = VWF collagen binding; VWF:PB $=$ VWF-platelet binding; LD-RIPA $=$ low-dose ristocetin-induced platelet aggregation; VWFpp $=$ VWF propeptide; $\downarrow=$ mildly decreased; $\downarrow \downarrow=$ moderately decreased; $\downarrow \downarrow \downarrow=$ greatly decreased. 